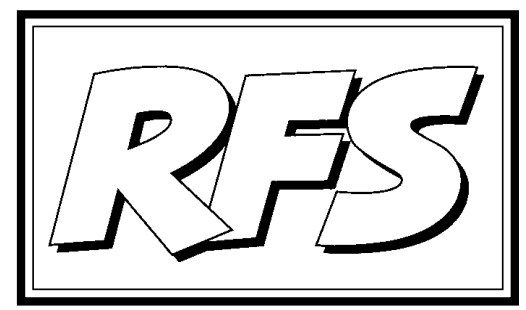

Revista de Fomento Social, 57 (2002), 11-24

\title{
Familia y trabajo
}

\section{Consejo de Redacción}

Hemos reunido en este número de la Revista de Fomento Social algunos artículos que abordan distintos temas relacionados con la familia y el trabajo. Aunque los números de nuestra revista no tienen normalmente un carácter monográfico, hay ocasiones en que el interés y la actualidad de un tema aconseja que le prestemos una atención especial. Es lo que ocurre con la familia. Por citar sólo cosas muy recientes: en la cumbre de Barcelona de la Unión Europea (marzo 2002) se insistió en "la necesidad de seguir trabajando a favor de la igualdad entre hombres y mujeres desarrollando medidas que faciliten el acceso y la permanencia de las mujeres en el mercado de trabajo, evitando las discriminaciones", para lo que se propone "incrementar las medidas dirigidas a la conciliación de la vida familiar y laboral, muy especialmente a través de la creación de servicios para el cuidado de la infancia y demás dependientes" (Declaración final); y unos días después el PSOE ha presentado un avance de plan de ayuda a la familia con vistas a su próximo programa electoral.

Ante la imposibilidad de abordar tan compleja temática, nosotros hemos querido seleccionar algunos aspectos de ella que consideramos más en sintonía con la especialización de nuestra revista: por eso nos hemos centrado especialmente en las relaciones de la familia con el trabajo. Más 
específicamente, el objeto de este editorial consiste en situar ese aspecto concreto seleccionado en la problemática actual de la familia, pasando revista a algunos de los cambios más significativos que ha sufrido en los últimos tiempos y sus consecuencias sobre el perfil actual de dicha institución. Precisamente algunos de esos cambios tienen mucho que ver con el ámbito laboral.

\section{¿Ocaso y fin de la familia?}

Hace algunas décadas - allá por los años 60- se puso de moda hablar del fin de la familia. La institución familiar parecía haber llegado al término de su historia.

Se mencionaban datos que ponían de manifiesto cómo la familia estaba atravesando una crisis sin precedentes, y precisamente ese modelo familiar - la familia nuclear- que había llegado a consolidarse como el más adaptado a las condiciones de la sociedad moderna, industrial y urbana. Frente al modelo antiguo -la familia extensa de claro sesgo patriarcal-, éste otro se caracterizaba por una mayor autonomía respecto al entorno, por un número más reducido de miembros (los cónyuges y pocos hijos) y por una disminución de las funciones de la familia (que ha ido transfiriendo cuestiones como la sanidad, la educación, la seguridad, el trabajo, etc. cada vez en mayor proporción a otras instituciones sociales).

¿Qué hechos podrían citarse como manifestaciones de esa crisis de la familia nuclear? Esencialmente se hablaba de los conflictos conyugales y el aumento de las rupturas matrimoniales, así como de las tensiones intergeneracionales en el seno de la familia. Si la reducción de funciones de la familia había concentrado el papel de ésta en el terreno afectivo (tan importante, por otra parte, para el desarrollo y la madurez de la persona), cuando las relaciones de mutua aceptación y comprensión se deterioraban, la familia empezaba a experimentar el sinsentido de mantener la convivencia bajo un mismo techo. Esa concentración de funciones no sólo hacía a muchas familias inestables y quebradizas, sino que convertía a la institución misma en inviable.

Evidentemente las características de la familia moderna, el modelo nuclear, la hacen mucho más frágil y vulnerable. Porque a esta reducción de sus funciones se une la falta de control externo y de sanción social, derivada de las nuevas condiciones de vida en el mundo urbano. Y se añaden también el 
mayor pluralismo y el talante más tolerante, que son otros ingredientes de la mentalidad moderna. Por fin hay que mencionar como otro factor determinante de esta vulnerabilidad el trabajo de la mujer fuera de casa, como tendremos ocasión de ver en seguida.

Pero crisis de la familia ¿equivale a fin de la familia? Hace unos 40 años se pensaba así. La familia había llegado a ser un ámbito excesivamente estrecho y cerrado, que terminaba por ahogar al individuo. Por eso, se empezaba a hablar de otras fórmulas como alternativas: la comuna, el kibutz... Fueron los años en que se puso de moda también visitar Israel para conocer de cerca el sistema socialista de los kibutz...

\section{Del fin de la familia a la diversificación de formas familiares}

En el momento actual, sin embargo, ya nadie habla del fin de la familia. ¿Pasó la tormenta y las aguas volvieron a su cauce? Eso sería simplificar demasiado las cosas...

Como ocurre con toda crisis, su superación no significa que las cosas vuelvan adonde estaban antes. Incluso hoy se sigue hablando de crisis de la familia. No es nuestra intención entrar ahora en ese debate. Demos o no por terminada la crisis, es innegable que la familia hoy, sociológicamente hablando, no es la misma que hace 40 años. Eso es lo que nos interesa analizar para comprender las relaciones de todo esto con el trabajo.

El primer dato a retener, de acuerdo con todos los estudios sociológicos recientes, es el creciente aprecio de que es objeto la institución familiar. La familia ha llegado a ser considerada por la gente, mayores pero también jóvenes, como algo insustituible en la vida humana. De todas las instituciones sociales, la familia es aquella que merece más confianza a las personas. Esta valoración queda especialmente confirmada en las encuestas sobre la juventud que realiza periódicamente la Fundación Santa María en España: contrasta en ellas el aprecio de los jóvenes hacia la familia con su falta de confianza creciente en otras instituciones, políticas desde luego, pero también religiosas.

Ahora bien, este aprecio renovado no debe interpretarse como una recuperación de la familia de antes. Porque la familia actual reviste características que difieren bastante de la de no hace muchos años. He aquí algunos datos que ilustran este cambio: se retrasa la edad de contraer matrimonio así como la llegada del primer hijo; disminuye el número de hijos por pareja, lo 
que muchas veces permite una mayor atención a éstos; se multiplican los fracasos y rupturas conyugales; aumenta el número de personas que rechazan el matrimonio, civil o religioso, y que prefieren la unión de hecho.

Volveremos sobre algunos de estos aspectos, pero de momento nos interesa fijar la atención en la frecuencia de las rupturas matrimoniales. Ese hecho nos pone en la pista sobre el talante de la familia de hoy y los motivos por los que se la aprecia: porque lo que se valora actualmente es una familia que llena ciertas expectativas afectivas y que, al mismo tiempo, esté dotada de una gran flexibilidad y tolerancia. Este diseño es el que algunos han comenzado a llamar una familia light.

$Y$ hay que reconocer que la familia que conocemos responde bastante a esta imagen: en ella los lazos afectivos son intensos -y es eso lo que la mantiene-, pero al mismo tiempo sus miembros viven con una notable autonomía, rayana muchas veces en la independencia. Esta cierta "disgregación" de la familia se manifiesta tanto en la relación entre los cónyuges como en la de éstos con los hijos: en cuanto a horarios, acondicionamiento del hogar, programación del ocio y acondicionamiento para ello (distribución de los aparatos de TV, por ejemplo), cada uno tiende a organizarse con una gran libertad y sin adaptarse casi nada a los demás.

En estas coordenadas se plantea si la familia mantiene su función socializadora tradicional. Porque es en la familia donde el niño se abre a la realidad social: a través de ella descubre e interioriza los usos y costumbres, los valores y puntos de vista de la sociedad en la que va a vivir. El carácter más abierto de la familia es, a la vez, causa y consecuencia de que la socialización (incluida la socialización primaria) se haga hoy por otros conductos que son complementarios a los del hogar.

Que esta familia más flexible sea, al mismo tiempo, más inestable no extrañará a nadie, porque los lazos que la mantienen unida son más débiles también. Por eso tampoco sorprende que las rupturas conyugales sean más frecuentes. $Y$ este es un gran reto para la familia misma en primer lugar, pero también para todas las instituciones que apuestan por su valor insustituible, entre las que ocupa un lugar preferente la Iglesia. Porque la inestabilidad de la familia no puede considerarse un valor, por mucho que seamos más tolerantes a la hora de justificar una ruptura para salir de situaciones que se han hecho de to do punto insostenibles. Siempre habrá que preguntarse qué factores contribuyen en cada familia concreta a fortalecerla o a debilitarla, para actuar en consecuencia. Desgraciadamente es frecuente que, cuando se 
plantea esto con la seriedad que requiere, resulta ya demasiado tarde.

Por otra parte, este modelo de familia más difundido coexiste con otras formas de convivencia: uniones de hecho, parejas homosexuales, familias monoparentales, etc. Hasta tal punto se han diversificado las formas de convivencia que no siempre se llega a un acuerdo entre los sociólogos para definir lo que es una familia e identificar sus rasgos esenciales.

\section{La evolución de la familia y el trabajo de la mujer fuera de casa}

Probablemente nuestros lectores habrán pensado ya que todos los cambios de la familia que hemos enumerado tienen no poco que ver con la incorporación masiva de la mujer al trabajo fuera decasa. Y están en lo cierto. Nos atreveríamos a decir que pocas cosas son tan determinantes para el cambio de la familia como el trabajo extradoméstico de la mujer. Es más, cabría decir que estos dos hechos se refuerzan recíprocamente: si el trabajo de la mujer está en la raíz de muchos cambios de la familia, éstos (y especialmente la inestabilidad) impulsa también a la mujer a buscar en el trabajo mayores dosis de seguridad.

En realidad, la salida del hogar por parte de la mujer para trabajar comenzó hace ya tiempo, pero sólo en décadas recientes ha adquirido dimensiones como para incidir en el modelo mismo de familia.

Que la mujer trabaje fuera de casa nos parece algo tan inevitable como justificado y deseable. Sus aspectos positivos son evidentes, por lo que carece de sentido discutirlo invocando las exigencias de la maternidad, por aludir al argumento de más peso entre todos los que se suelen escuchar.

Ahora bien, este hecho tiene unas consecuencias que no siempre se reconocen y unas exigencias que con frecuencia no se asumen.

La consecuencia más importante es que el trabajo da a la mujer una seguridad psicológica y económica, una autonomía y una capacidad de valerse por sí misma en la sociedad que no tenía cuando pasaba gran parte de su existencia recluida en el hogar, por muy valiosas y meritorias que fueran las tareas que en él desempeñaba. Se siguen además de ahí una mayor igualdad efectiva entre el hombre y la mujer y una cierta pérdida de la distinción de funciones, que tanto ha marcado durante siglos a la familia.

Si en conjunto podemos afirmar que el trabajo de la mujer es positivo, no es superfluo subrayar que tiene entre sus costes o riesgos el aumentar la 
inestabilidad de la pareja dada la tradición anterior. Y para poder reducir esos riesgos no hay otro camino que el asumir responsablemente las consecuencias inevitables o las exigencias que comporta la incorporación masiva de la mujer al trabajo fuera del hogar. Este es, en nuestra opinión, uno de los retos indudables que debe afrontar la familia hoy y que no siempre es conveniente asumido.

Si la mujer tiene que compartir su tiempo y sus energías en dos frentes (el familiar y el laboral), ¿no exige esto que el varón haga algo semejante? Sin embargo, los datos disponibles indican que las tareas domésticas y familiares siguen recayendo masivamente sobre la mujer, mientras que el varón se resiste a asumir la porción que le correspondería en una distribución más equitativa. El peso de la cultura y de la educación recibida es todavía muy fuerte, dificultando el paso a una distribución detareas más equilibrada. Pero la consecuencia es evidente: en estas condiciones es el desarrollo profesional de la mujer el que se encontrará siempre limitado. Ahora bien, ¿por qué ha de ser a ella a quien le toque sacrificar su carrera para atender a las tareas domésticas o familiares? ¿no cabría abordar ese inevitable sacrificio desde otros presupuestos?

No se aboga aquí por una total igualación como la única forma de superar de una vez las discriminaciones entre hombre y mujer. Sería prolijo adentrarnos en el debate sobre si los papeles del padre y de la madre son intercambiables al cien por cien. Nos parece en todo caso que una diferenciación de funciones tendría la ventaja de la complementariedad. La discriminación sólo se daría cuando faltaran las razones objetivas para la diferenciación: concretamente, si la madre tuviera que seguir asumiendo en tiempo y en energías una proporción injustificadamente más elevada de las tareas del hogar.

Tampoco se trata aquí de minusvalorar la función paterno-materna como si fuera sólo una carga a soportar por personas que tienen el centro de su vida en otro lugar. Pero esto no debe ocultar un hecho que, en la práctica cotidiana, cuesta mucho reconocer: quela paternidad y la maternidad exigen un tiempo, que hay que detraer de otras actividades, y concretamente de la vida profesional y laboral. En este sentido no se puede ignorar el conflicto

1 Sobre este conflicto ofrece sugerentes reflexiones y propuestas para afrontar esta cuestión el artículo de J osé A. ARIZA, que publicamos en el presente número de nuestra revista: El dilema del equilibrio vida personal versus vida profesional: un enfoque de recursos humanos. 
entre tiempo de trabajo y tiempo personal y familiar ${ }^{1}$. ¿Podría ser el contrato a tiempo parcial una salida para uno de los cónyuges (no siempre la mujer...), al menos durante la época en que la atención a los hijos exige mayor dedicación? Sin duda que sí. Pero tampoco podemos olvidar que en un marco tan competitivo como el actual, donde la inestabilidad y la temporalidad del trabajo son tan altas, el valor del tiempo de trabajo crece y entra en colisión con cualquier otra ocupación.

Pero insistimos en que, según los datos sociológicos disponibles, los hijos no son vividos como una carga. Dichos estudios constatan, en contraste con otros tiempos y en contra de lo que algunos piensan, que las actitudes hacia los hijos son, no sólo muy favorables, sin más desinteresadas: concretamente, que el hijo es considerado desde la gratuidad, y no como una fuente de riqueza o de seguridad para el futuro de unos padres ya ancianos (cosa que sigue ocurriendo todavía en países marcados por la pobreza). En la actualidad un hijo es más una fuente de gastos (y cuantiosos) que de ingresos. Pero ésta no es la motivación más decisiva para llegar a ser padres, aunque pueda condicionar la decisión sobre el número de hijos de un matrimonio, sino la satisfacción misma de dar la vida.

Algo parecido hay que decir de la conyugalidad. También ésta, como la paternidad y la maternidad, exige tiempo, y un tiempo que está en competencia con el que reclama el trabajo. En este caso, además, la utilidad de ese tiempo - menos aún que en el de la paternidad- no puede medirse con los cánones de la productividad que el mundo económico y profesional nos impone. Por eso es preciso comprender que la utilidad comparada del tiempo de trabajo y del tiempo para la familia es difícil de medir: y es que se trata de ámbitos vitales que se rigen por lógicas y por criterios muy diferentes.

\section{Familia, trabajo de la mujer y ordenamiento jurídico}

La tarea de adaptar la vida de familia a las nuevas exigencias derivadas del trabajo femenino no es responsabilidad exclusiva de los cónyuges. La sociedad debe tomar también cartas en el asunto, y el Estado tiene que adaptar sus leyes a estas nuevas circunstancias.

No puede ignorarse que la legislación de un país, y concretamente la legislación laboral, responde a una determinada realidad histórica y social. El modelo de trabajo sobre el que se fue construyendo la actual legislación 
laboral y social se apoyaba en un tipo de familia donde los papeles quedaban claramente distribuidos entre el hombre y la mujer. Pero hoy no es ya esa la realidad a la que se aplican las leyes laborales.

Es cierto que se han hecho adaptaciones que obedecen a las exigencias derivadas del trabajo extradoméstico de la mujer. Pero, ¿no son sólo cambios puntuales? ¿Cuáles son, concretamente, esos cambios?

Vamos a referirnos a continuación a algunos de ellos, que nos parecen los más significativos. Nos limitaremos, además, al caso español, arrancando de la base que ofrece la Constitución de 1978 para estudiar luego la legislación que creemos de mayor interés.

\section{La protección de la mujer en la Constitución de 1978}

Para comprender la atención que se presta a la familia en el ordenamiento jurídico en general hay que remontarse sin duda a la Constitución de Weimar de 1919: fue en ella donde por primera vez se plasmó el Estado del bienestar, que luego se consolidaría tras la Segunda Guerra Mundial. Y es en este nuevo marco donde la familia adquiere un valor políticamente estimable. En España el primer eco de estos planteamientos lo encontramos en el Anteproyecto de Constitución de la Dictadura en 1929.

La Constitución española de 1978 sigue en este punto los precedentes de algunas constituciones europeas, fundamentalmente la italiana de 1947 y la de Bonn de 23 de mayo de 1949 que realizan un tratamiento programático pero bastante generoso de la institución familiar, más generoso sin duda que los de nuestra Constitución republicana de 1931 o los de la legislación del franquismo (Fuero de los Españoles de 1945, Ley de Principios del Movimiento Nacional de 1958 y Ley Orgánica del Estado de 1967).

La vigente Constitución española considera que la familia trasciende a la esfera privada de las personas que la integran y, como tal, tiene una función e importancia social. En atención a ello el art. 39 señala que los poderes públicos aseguran la protección social, económica y jurídica de la familia. Sin embargo, nuestro texto constitucional no concreta el sentido de esta protección familiar, como sí lo hace, por ejemplo la Constitución portuguesa, ésta señala expresamente que dicha protección familiar consiste en el logro de la independencia social y económica de la unidad familiar, la asistencia materno-infantil y a la ancianidad, la cooperación del Estado en la educación de los hijos, etc. 
Tampoco concreta la Constitución de 1978 el tipo de familia al que se refiere, sino que opta por diseñar una fórmula suficientemente amplia para comprender cualquier género de transformación que pueda experimentar la familia. Esto significa que nuestra Ley Fundamental no identifica a la familia a la que manda proteger con la que tiene origen en el matrimonio, aunque sea ésta la más relevante en nuestra cultura y en la realidad de los comportamientos sociales. Esta ambigüedad permite una más fácil adaptación a los cambios y a la diversificación de formas familiares, como lo confirma, por ejemplo, la legislación laboral al equiparar la protección del matrimonio y de las uniones de hecho a efectos laborales.

El respeto al tratamiento constitucional del principio de protección a la familia exige al legislador, en esencia, la especial protección a las madres y a los hijos menores. En este sentido, el Estatuto de los Trabajadores otorga derechos especiales a la madre trabajadora para que pueda atender a su hijo recién nacido (art. 39, 2-3 CE): para proteger a la madre trabajadora y garantizar el cuidado del recién nacido se aligera a la mujer trabajadora de las cargas derivadas de su condición biológica y de su papel en la sociedad.

\section{La protección de los intereses familiares en el ámbito laboral: la Ley de 1989}

En el planteamiento normativo anterior a 1989 (incluidas la Ley de Relaciones Laborales de 1976 y el Estatuto de los trabajadores de 1980) la maternidad era considerada como un proceso (embarazo, alumbramiento y puerperio) encaminado a la generación de un nuevo $\mathrm{ser}^{2}$. El interés normativo se orientaba, en consecuencia, a la adopción de medidas que garantizasen el buen término de dicho proceso. Estas medidas se concretaban en: un descanso maternal pre- y postparto, prestaciones médico-sanitarias y prestaciones de sostén económico durante los diferentes períodos. Todas estas medidas laborales eran de carácter proteccionista y unidireccional: pretendían beneficiar a la madre trabajadora y a su hijo, facilitando la adecuada atención de su salud, y al establecimiento de una relación positiva entre ambos. Su coste recayó fundamentalmente en el empresario y, en menor medida, también en el Estado.

2 Sobre los antecedentes históricos de esta cuestión véase en este mismo número el artículo de Pilar Núñez-Cortés Contreras, Los orígenes de la protección de la maternidad. 
La Ley 3/1989, de 3 de marzo, por la que se amplia a dieciséis semanas el permiso por maternidad y se establecen medidas para favorecer la igualdad de trato de la mujer en el trabajo, introdujo un importante cambio en el enfoque normativo de la protección por maternidad propiciado por la nueva realidad socio económica y laboral que atañe a la mujer, a la familia y a la sociedad en su conjunto. Su principal novedad consistía en permitir al padre trabajador disfrutar de una parte del descanso por maternidad.

Tal novedad se concreta en la consideración del período de descanso por maternidad como un tiempo de adaptación de la familia a la nueva realidad producida tras el nacimiento del hijo. Esta posibilidad de transferir al padre una parte del descanso por el alumbramiento responde a la finalidad de protección a la familia y de promoción de la madre trabajadora.

Sin embargo, al concederle este derecho al padre, la norma no le situó en el mismo nivel de protección que a la madre, de manera que ambos disfrutaran del permiso indistintamente, como sucede en los supuestos de adopción y excedencia por cuidado de hijos. La filosofía de fondo es otra: se trata de una ventaja legal para la trabajadora de la que se puede hacer partícipe al padre con objeto de favorecer profesionalmente a la madre, sin perjudicar al hijo. De este modo la protección por maternidad se concretará en algunas reglas especiales para la maternidad biológica, pero que al mismo tiempo tiende a igualar el régimen del trabajo masculino y femenino. Un efecto pretendido de este planteamiento será evitar que los empresarios sean más partidarios de contratar a hombres que a mujeres.

Por consiguiente, a partir de 1989, nuestra regulación lleva implícita la finalidad de repartir entre los progenitores no sólo las cargas domésticas derivadas del nacimiento y la crianza de un hijo, sino también los riesgos profesionales que este hecho conlleva. En un verdadero ejercicio de igualdad real, la Ley 3/89 favoreció la posibilidad de que los padres se pusieran de acuerdo en repartir el riesgo profesional, cuando para la mujer fuera muy elevado, soportándolo entre ambos. Las innovaciones incorporadas al ordenamiento laboral perseguían favorecer la compatibilidad entre la realización del trabajo y el ejercicio de la maternidad y la paternidad, con la intención de que la atención al hijo no perjudicase profesionalmente a sus progenitores ${ }^{3}$.

3 En la práctica, los efectos de esta legislación han sido pobres: según datos de la Encuesta de Población Activa, para el segundo trimestre de 1998, sólo el 1,4\% de los padres se habían acogido a esta posibilidad. 
Finalmente hemos de destacar que tampoco el "interés del empresario" fue adecuadamente protegido por la regulación de 1989: las cargas que por razón de la maternidad recaían sobre el empresario siguieron siendo las mismas, si no mayores. En este sentido, no se facilitó al empleador el recurso (incluso temporalmente subvencionado) a la contratación de trabajadores interinos, con la finalidad de contrarrestar el impacto negativo de la mayor carestía de la contratación de mano de obra femenina. Ha sido preciso esperar hasta 1998 para que algunas de estas medidas sean adoptadas: por ejemplo, las bonificaciones y exenciones en las cuotas a la Seguridad Social del trabajador contratado para cubrir la ausencia por maternidad (el llamado "coste cero de la maternidad").

\section{La conciliación de la vida familiar y laboral: la Ley de 1999}

La más reciente Ley 39/99, de 5 de noviembre, sobre Conciliación de la vida familiar y laboral de las personas trabajadoras, está en continuidad con las normas anteriores, pero se producen algunos cambios respecto a la intensidad con que, en particular, se protege alguno de ellos. Concretamente, esta ley constituye un encomiable esfuerzo por lograr un reparto equilibrado de responsabilidades en la vida profesional y en la privada: más en particular, busca garantizar la permanencia de la mujer en el mercado de trabajo cuando sobrevienen las cargas familiares.

En este sentido, la principal novedad consiste en ampliar el disfrute paterno de la licencia, que puede llegar a ser de diez semanas ininterrumpidas 0 , incluso, dieciséis en caso de fallecimiento de la madre; además, la Ley flexibiliza el disfrute del permiso contemplando la posibilidad de que sea sucesivo o simultáneo con la madre. Con ello se pretende incentivar el disfrute del mismo por el varón, a la vez que posibilitar la vuelta al trabajo de la mujer antes de la finalización de la licencia. La posibilidad de reincorporación anticipada beneficiará profesionalmente a la trabajadora sin que suponga un perjuicio para la atención del recién nacido.

Por otra parte, esta nueva ley refuerza la estabilidad en el empleo de la trabajadora, poco favorecida en las anteriores regulaciones. La maternidad y el ejercicio de las responsabilidades familiares se cuentan entre las situaciones más delicadas para la estabilidad en el empleo de la trabajadora. El análisis de la jurisprudencia de los Tribunales Superiores de Justicia de los últimos diez años muestra que el período más problemático es el que se 
extiende desde que el empresario conoce el embarazo hasta que la trabajadora opta por el disfrute del período voluntario de descanso anterior al parto. En no pocas ocasiones las alteraciones en la salud de la madre en los primeros momentos del embarazo son utilizadas por el empresario para poner en marcha mecanismos encaminados a la resolución de su contrato, sea éste definitivo, temporal o de prueba. Por eso la ley de 1999 ha considerado preciso reforzar los mecanismos de tutela frente a los despidos fundamentados precisamente en el ejercicio de los derechos relacionados con la maternidad y el ejercicio de las responsabilidades familiares. En este sentido, el despido que tenga por causa este "factor diferencial" incurre en una discriminación directa por razón de sexo. Con esto se pretende, no sólo reforzar la especial tutela de la que es acreedora la mujer trabajadora, sino también fomentar la natalidad, lo que es preocupación común a todas las sociedades occidentales.

Conviene añadir además que la ley que comentamos se inspira claramente en este aspecto en la normativa internacional: en concreto, en la Directiva 92/ 85, de 19 de octubre, así como en el reciente Convenio núm. 183 de la OIT 4. Nuestra regulación ha optado por una fórmula de protección de los trabajadores con responsabilidades familiares que consiste en presumir la ilegalidad del despido de éstos cuando ejercen los derechos que las normas les reconocen por tales circunstancias familiares. De esta manera se produce una especie de blindaje del contrato desde el inicio del embarazo hasta el final de la excedencia por cuidado de hijos, quesi agotara su extensión puede extenderse hasta los tres años del hijo.

\section{De la legislación laboral a las políticas sociales y familiares}

Hemos analizado dos normas legales recientes que muestran cómo se van dando algunos pasos, desde la legislación laboral, para una mejor articulación del trabajo y familia atendiendo especialmente a la nueva integración social de la mujer ${ }^{5}$. Pero el Derecho laboral no es suficiente para esto. Así lo reconocía el dictamen del Consejo Económico y Social sobre el Anteproyecto de la citada Ley 39/99 cuando afirmaba:

4 Véase el texto completo de dicho convenio en este mismo número en la página 183.

5 Otros aspectos del tema han sido tratados en este número de nuestra revista, desde el punto de vista del derecho laboral, por TeResa Velasco Portero: Incidencia de la vida familiar sobre el contrato de trabajo. 


\begin{abstract}
“Complemento necesario para que la conciliación de la vida familiar y laboral pueda efectivamente producirse es promover la creación de servicios de atención a las personas, tal como se recoge en las orientaciones de empleo incluidas en el cuarto pilar de igualdad sobre Igualdad de Oportunidades. Los nuevos yacimientos de empleo que surgen de las nuevas demandas de cuidados profesionales a las personas -niños, enfermos, mayores, etc.- deben recibir el impulso de las políticas de empleo y de fomento de la Igualdad de Oportunidades. En esta línea el Consejo echa en falta una referencia concreta a cómo se van a insertar las medias legislativas propuestas en una política más amplia que aborde el conjunto del problema".
\end{abstract}

Efectivamente, el tema es tan complejo y sobre el que inciden tan numerosos aspectos metalaborales, que resulta insostenible el intento de encomendar su resolución a la legislación laboral, cosa que ocurre como resultado de una arraigada inercia histórica. Por lo demás, este enfoque del problema perjudica abiertamente al empresario, sobre quien tienden a recaer los costes organizativos y también algunos de los económicos producidos por la compatibilización de la vida profesional y familiar. Un tratamiento más polivalente de estos problemas permitiría integrarlos en el conjunto de las políticas sociales, lo que permitiría una participación más efectiva del Estado también en el reparto de los costes.

La política fiscal tiene también aquí una importancia decisiva a través de las deducciones por cargas familiares en el IRPF, que se extiende a los hijos y a otros miembros de la familia, o de la posibilidad de declaración separada de los cónyuges.

En el capítulo de las políticas sociales es donde nuestro país es menos generoso. Las ayudas por cargas familiares son muy exiguas, aunque el tema parece que resurge hoy, aunque sea en relación con la alarmante caída de las tasas de natalidad. Faltan también otras ayudas, por ejemplo ayudas por cargas de mayores (no sólo económicas, sino también de otros servicios). Por último tampoco habría que olvidar que un elemento que condiciona la creación de una familia es la posibilidad de disponer de una vivienda, ya que el precio actual de los inmuebles es una pesada cargas para muchas parejas: aunque los planes de vivienda y las normas del mercado hipotecario tratan de facilitar la compra de una vivienda, hay que reconocer que la carga financiera de su adquisición sigue siendo prohibitiva en bastantes casos.

He ahí algunos ejemplos que son como botones de muestra de la amplitud de frentes que debe contemplar una verdadera política de familia. Los apuntamos solamente, reconocien do que merecerían más atención y debate. 


\section{Conclusión}

Aparte de lo que se oiga en muchos discursos y declaraciones, la verdad es que España no destaca por su preocupación en favor del bienestar de la familia. Nuestra política de familia es anticuada y se basa en esquemas ideológicos que ya no se corresponden con la realidad. En las últimas décadas, nuestros gobiernos no han sido muy sensibles a los cambios en el papel social de la mujer, ni a las consecuencias de esto para la familia. Y todo ello debe ser denunciado como una forma implícita de política antifamiliar.

Pasar de las declaraciones a los hechos implica abordar la siempre espinosa cuestión de los recursos económicos que habría que asignar a estas políticas. Y ya sabemos que no corren buenos tiempos para las políticas sociales, cualquiera que sea su signo. Las restricciones presupuestarias, hoy tan fuertes, serían un obstáculo más para afrontar las reformas que la historia nos impone. ¿Cabría hacer frente a todas esas dificultades insistiendo en que una política moderna de familia es una inversión para el futuro? Sin embargo este argumento sería menos creíble si no fuera acompañado de un esfuerzo de toda la sociedad por avanzar, no sólo en la verdadera integración laboral de la mujer, sino en los cambios de mentalidad y de organización que esta nueva situación exige a las familias. 